\title{
Retinal locus and acuity in visual information processing
}

\author{
CHARLES W. ERIKSEN and DEREK W. SCHULTZ \\ University of Ilinois, Champaign/Urbana, Illinois 61820
}

\begin{abstract}
Much recent visual information processing research has employed linear or rectangular letter displays subtending up to $8 \mathrm{deg}$ of visual angle in width. Subsequent theory based on these data has assumed the simultaneous availability to some central processor of all $n$ targets. Data on retinal acuity suggest that this assumption is gratuitous. Six subjects served in a tachistoscopic speeded letter recognition task wherein display luminance, retinal target locus, number of alternative target positions, and stimulus degradation by superimposition of a dot grid were manipulated orthogonally. Identification reaction times increased on the order of $100 \mathrm{msec}$ as targets were located $3 \mathrm{deg}$ from the fovea center, and results under convergent operations in the design suggested that these reaction time increases were a manifestation of peripheral stimulus degradation factors (such as acuity, masking, and luminance) rather than more central cognitive processes.
\end{abstract}

Much recent visual information processing research concerning attentional capacity and processing rate has employed linear or rectangular letter displays subtending as much as 8 deg of visual angle (Bjork \& Estes, 1973; Egeth, Jonides, \& Wall, 1972; Estes, 1974; Shaw \& Weigel, 1973). Theory based on data from these studies has frequently assumed simultaneous availability of all letters in the display to some central cognitive processor or attentional filter. There is considerable evidence available to suggest that such an assumption is seriously in error. First, acuity even within the fovea drops rather markedly as the locus of the stimulus is moved from the foveal center (Riggs, 1965). Second, neural bundles become increasingly interconnected outward across the retina, thereby degrading edge and contour resolution. Moreover, Sternberg (1969) has shown that the reaction time (RT) to visual forms increases with the degradation of the stimulus, and his experiments further suggest that the locus of this increase in RT is on the input side.

The effect of the retinal locus of a signal upon RT has a long history (Hall \& von Kries, 1879; Poffenberger, 1912). These studies unfortunately used simple RT, usually to a light flash, and were mainly concerned with differences in RT to foveal vs. extrafoveal stimulation.

An exception is the recent experiment by Lefton and Haber (1974). These investigators were also concerned with the critical assumption made by many information processing theorists that all $\mathrm{n}$ letters in a simultaneously presented display were simultaneously available to a central processor. Lefton and Haber measured the subject's RT for "same" and "different" judgements to two letters presented simultaneously. The retinal loci for fovea center to $\pm 4 \mathrm{deg}$ of angle were explored. Though RT varied nearly $100 \mathrm{msec}$ from fovea center to $4 \mathrm{deg}$ outward, there were significant nonmonotonic effects in their data. The reasons for the nonmonotonicity were not clear, but perhaps reflect the judgmental nature of the task, which may have interacted with stimulus degradation.
A more central concern to information processing theories is the time for an identification or recognition response. We would like to know the effect of retinal locus upon how quickly identification or recognition of information is available to a central processor, so it seems preferable to employ a response that avoids other stages of cognitive processing.

The present experiment's subjects vocalized as rapidly as possible which of four target letters appeared at the foveal center or in locations plus and minus $3 \mathrm{deg}$ removed on the horizontal meridian. Since masking or other forms of stimulus degradation are frequently employed in visual information processing experiments, we also investigated whether stimulus degradation interacted with retinal locus by degrading the letter stimuli through superimposition of a dot matrix in one condition and by luminance manipulation in another condition. Target point uncertainty was also manipulated in two conditions: a three-position condition, where the target could appear at the fovea or at either one of two other positions; and a seven-position condition where, in addition to the fovea, the target could appear in any one of three positions on either side.

\section{METHOD}

\section{Subjects}

Six University of Illinois graduate and undergraduate students served as paid volunteers. All had corrected to normal vision and prior experience with tachistoscopic displays.

\footnotetext{
Apparatus and Stimuli

Trials were conducted on a Scientific Prototype Model GA three-field tachistoscope, modified with Sylvania F4T5/CWX fluorescent lamps. Luminances in the two fields were maintained at specified levels as measured by a Spectra spot photometer.

The adaptation field, with a fixation cross subtending $.24 \mathrm{deg}$ of visual angle, remained on unless another field was activated. Trials were initiated by the subject pressing a hand microswitch, which triggered the t-scope and a LaFayette digital counter with the onset of the target channel. Voice RT was measured in milliseconds by activation of a Scientific Prototype voice key.
} 
Thirty-six stimulus displays were constructed on white vinyl cards with 18-point black Futura Demi Bold Paratipe (No. 11316) letters, $\mathrm{A}, \mathrm{O}, \mathrm{H}$, and $\mathrm{M}$, subtending . $20 \mathrm{deg}$ of visual angle in height. For each display, a single target letter was positioned along a horizontal axis extending $3 \mathrm{deg}$ of visual angle from either side of the fixation cross. Two positional uncertainty conditions were employed: the single target could appear in either one of three or seven equally spaced positions along the 6-deg horizontal axis. Both conditions included presentations at 0 -deg displacement from the adaptation cross and 3-deg displacement left or right of the adaptation cross. The seven-position condition also employed presentations at 2 and $1 \mathrm{deg}$ left and right from fixation.

Stimulus degradation was accomplished by placing 25 1/32-in. Paratipe dots (obtained from Paratipe No. 55068) on clear vinyl cards in 5 by 5 cell square patterns subtending $.6 \mathrm{deg}$ of visual angle in both width and height. To maintain constant luminance in both fields, both the adaptation cross and the target letter cards were presented with clear vinyl cards placed in front of them. Under the degraded condition, the dot grid was placed in front of the target and in the same tachistoscopic field.

\section{Procedure}

Each subject participated in six experimental sessions, two under the three-position condition and four under the sevenposition condition. A session under the three-position condition consisted of six blocks of 24 trials. Alternate blocks were degraded during each session. Additionally, three sessions (one under the three-position condition and two under the seven-position condition) were run at 34 candles/ $\mathrm{M}^{2}$ and three at a lower luminance $\left(6.8\right.$ candles $\left./ \mathrm{M}^{2}\right)$. In the seven-position condition, six blocks of 26 trials were conducted. Degradation and luminance were also manipulated as in the three-position condition described above. Spacing conditions (three vs. seven) were counterbalanced in a randomized Latin square over the six sessions for each of the six subjects. Luminance and degradation conditions were also counterbalanced both within and across subjects. Target letters appeared in random order and were randomly positioned with the constraint that each letter appeared in each position with equal frequency within a spacing condition. Stimulus duration was a constant $175 \mathrm{msec}$ for all conditions.

Each subject served in several practice sessions, followed by the experimental sessions. In each session, several minutes of dark adaptation were followed by 10 warmup trials chosen in a random block. The subject was instructed to initiate a trial when the fixation cross appeared in good focus and to report the target letter as quickly, distinctly, and accurately as possible. Trials were conducted binocularly, and feedback in terms of RT in milliseconds followed each trial. Most sessions lasted $50 \mathrm{~min}$.

\section{RESULTS AND DISCUSSION}

Results were analyzed separately for the three- and the seven-position conditions in a four-way ANOVA (subjects by retinal locus by luminance by degradation). For both conditions the main effects of retinal locus and stimulus degradation were significant $(F=12.16$, $\mathrm{df}=6 / 30, \mathrm{p}<.001$ and $\mathrm{F}=21.52, \mathrm{df}=2 / 10, \mathrm{p}<.001$ for retinal locus; $F=12.53, \mathrm{df}=1 / 5, \mathrm{p}<.05$ and $F=7.68, \mathrm{df}=1 / 5, \mathrm{p}<.05$ for stimulus degradation in the three- and seven-position conditions, respectively). In neither analysis was there a significant effect for luminance, nor did this variable interact with retinal locus or stimulus degradation. The main effect for

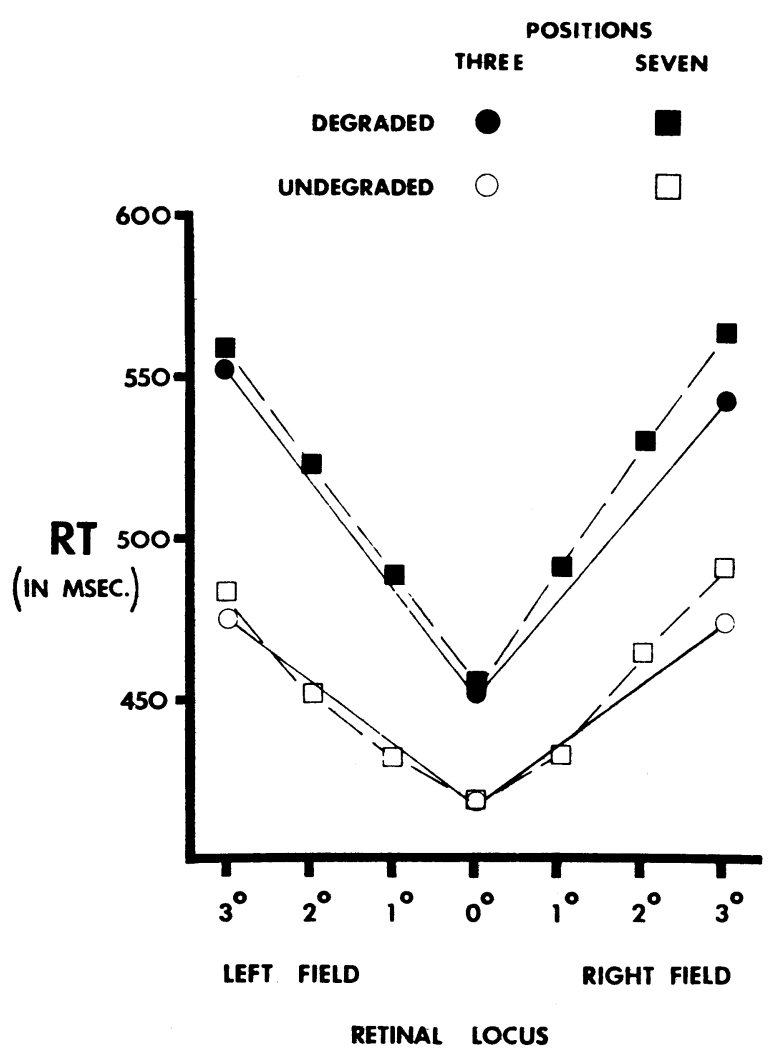

Figure 1. Mean latency to target recognition as a function of retinal locus, positional uncertainty, and stimulus degradation. Commensurate with the nonsignificant effect of luminance, data have been pooled over that factor.

subjects was, of course, significant, as were subject interactions with retinal locus, luminance, and stimulus degradation $(\mathrm{p}<.001)$.

Test of the positional uncertainty variable was obtained by comparing the three- and the seven-position conditions in an analysis of variance using the three retinal loci common to both conditions ( $0 \mathrm{deg}$ and $+/-3 \mathrm{deg})$. The main effects and interactions that were significant on the within-condition analyses were, of course, again significant, but the effect for position uncertainty did not approach significance $(F=.5546$, $\mathrm{df}=1 / 5, \mathrm{p}>.40$ ).

In Figure 1, the mean RT in identifying target letters is shown as a function of retinal locus for the three- and the seven-position conditions. The data are presented separately for the degraded and the nondegraded stimulus conditions but, in keeping with the lack of a significant or even suggestive effect of luminance, the data have been pooled across luminance levels. As is apparent from the figure, there is a pronounced effect upon RT as the target is moved from the foveal center to 3 deg along the horizontal meridian: RT increases on the order of $100 \mathrm{msec}$. Further, when the stimulus is degraded by the superimposition of a dot grid over the target letter, moving the target off the foveal center has a more 
pronounced effect. That is, the RT increase as the target is moved from the foveal center is greater for a degraded stimulus than for a nondegraded target.

The magnitude of the effects of foveal locus upon RT is comparable to that obtained by Lefton and Haber (1974). Our data differ, however, in that RT is a monotonically increasing function of distance from foveal center, whereas Lefton and Haber found significant irregularities in the function. Our data are commensurate with what would be expected from retinal acuity functions (Riggs, 1965; Wertheim, 1894). The irregularities in the Lefton and Haber functions may be due to the same/different judgment that was required of their subjects. As foveal areas of less acuity were stimulated, their subjects may have changed their criterion or have shifted to different cues in making same/different judgments.

Effect of retinal locus upon the identification time for visual forms can logically be ascribed to two different processes. First of all, it is possible that neural transmission time from the retina to higher visual processing centers varies as a function of retinal locus. Indeed, research has shown that such differences in transmission time do exist (Doty, 1958; Sweet, 1953; Kappauf, Note 1). However, the magnitude of these differences in transmission time is appreciably less within the fovea than the approximately $100 \mathrm{msec}$ obtained in our data and those of Lefton and Haber (1974).

A more likely basis for the increase in recognition time is the degradation in the information provided higher processing centers as the periphery of the fovea and nonfoveal regions is stimulated. One of the basic facts about the visual system is its temporal-integrative nature (Ganz, 1975). Kahneman and his associates (Kahneman, 1964, 1965; Kahneman \& Norman, 1964; Kahneman, Norman, \& Kubovy, 1967) have shown that time-intensity reciprocity for visual forms extends for several hundred milliseconds. The increase in time necessary for recognition as stimulus quality decreases may reflect the need of a central processor to wait longer for energy to be summed in the visual system in order to resolve or compensate for the decreased stimulus quality or degradation.

As we have described elsewhere (Eriksen \& Schultz, Note 2), due to time-intensity reciprocity the information available in the primary visual projection area develops over time in a manner analogous to the development of a photographic print. That is, gross or highly discriminable features become available to a central processor before the finer detail, which must await the integration of more energy over time in order to resolve the higher levels of acuity that they require. As stimuli fall on retinal areas of less acuity, a longer period of energy summation would be required in order to compensate for the decreased acuity.

The results obtained with stimulus degradation manipulation in the present experiment are commensurate with this interpretation, but the failure to find luminance level effects is not. However, the failure of the luminance manipulation to significantly affect RT at any retinal locus may have been due to the rather restricted range of luminance values employed.

Regardless of the extent to which the present effects are due to differences in neural transmission time for different retinal loci or the need for increased energy summation time, the data clearly demonstrate that the peripheral sense organ, at least in vision, plays an important role in limiting overloads on subsequent information processing stages. In our concern with the cognitive stages in visual information processing, we are apt to overlook the role of the sense organ itself in selecting and limiting inputs. The present data suggest that, even when the visual system is stimulated simultaneously with a multiletter display, the characteristics of the sense organ insure that the information in the display is available to central processors or stages in a temporally distributed manner.

\section{REFERENCE NOTES}

1. Kappauf, W. E. On- and off-latencies in visual perception: Effects of luminance, wavelength, and retinal location. (Report No.4) Champaign, Ill: University of Illinois, November 1967.

2. Eriksen, C. W., \& Schultz, D. W. Temporal factors in visual information processing. Paper presented at the Seventh International Symposium on Attention and Performance, Marseilles, France, August 1976.

\section{REFERENCES}

BJORK, E., \& EsTES, W. K. Letter identification in relation to linguistic context and masking conditions. Memory \& Cognition, 1973, 1, 217-223.

Doty, R. W. Potentials evoked in cat cerebral cortex by defuse and by punctiform photic stimuli. Journal of Neurophysiology, 1958, 21, 437-464.

Egeth, H., Jonides, J., \& Wall, S. Parallel processing of multielement displays. Cognitive Psychology, 1972, 3, 694-698.

Estes, W. K. Redundancy of noise elements and signals in visual detection of letters. Perception \& Psychophysics, 1974, 16, 53-60.

Ganz, L. Temporal factors in visual perception. In E. C. Carterette \& M. P. Friedman (Eds.) Handbook of perception (Vol. 1). New York: Academic Press, 1975. Pp. 169-231.

Hall, G. S., \& von Krues, J. Über die abhangigkeit der reactionzeit vom ort des reizes. Archives of Anatomy and Physiology: Leipzig Supplement, 1879, 1-10.

KaHNEman, D. Temporal summation in an acuity task at different energy levels-a study of the determinants of summation. Vision Research, 1964, 4, 557-566.

Kahneman, D. Exposure duration and effective figure ground contrast. Quarterly Journal of Experimental Psychology, 1965, 17, 308-314.

Kahneman, D., \& Norman, J. The time-intensity relation in visual perception as a function of the observer's task. Journal of Experimental Psychology, 1964, 68, 215-220. 
Kahneman, D., Norman, J., \& Kubovy, M. The critical duration for the resolution of form: Centrally or peripherally determined? Journal of Experimental Psychology, 1967, 73, 323-327.

LEFTON, L., \& HABER, R. N. Information extraction from different retinal locations. Journal of Experimental Psychology, 1974, 102, 975-980.

Poffenberger, A. T. Reaction time to retinal stimulation with special reference to time lost in conduction through nerve centers. Archives of Psychology, 1912, 3, 1-73.

RIgGs, L. A. Visual acuity. In C. H. Graham (Ed) Vision and visual perception. New York: Wiley, 1965. Pp. 321-419.

Shaw, P., \& Weigel, G. Effects of bars and blanks on recognition of words and non-words embedded in a row of letters. Perception \& Psychophysics, 1973, 14, 117-124.
Sternberg, S. Memory scanning: Mental processes revealed by reaction-time experiments. American Scientist, 1969, 57, 421-457.

SwEET, A. L. Temporal discrimination by the human eye. American Journal of Psychology, 1953, 66, 185-198.

WERTHEIM, T. Ueber die indirecte schsharfe. Zeitschrifte fur Psychologie und Physiologie der Sinnesorgane, 1894, 1, 172-187.

(Received for publication September 22, 1976.) 